\title{
Distinct mechanisms of axonal globule formation in mice expressing human wild type a-synuclein or dementia with Lewy bodies-linked P123H ß-synuclein
}

Akio Sekigawa', Masayo Fujita ${ }^{1}$, Kazunari Sekiyama', Yoshiki Takamatsu' ${ }^{1}$, Taku Hatano ${ }^{2}$, Edward Rockenstein ${ }^{3}$, Albert R La Spada ${ }^{4,5}$, Eliezer Masliah ${ }^{3}$ and Makoto Hashimoto ${ }^{1^{*}}$

\begin{abstract}
Background: Axonopathy is critical in the early pathogenesis of neurodegenerative diseases, including Parkinson's disease (PD) and dementia with Lewy bodies (DLB). Axonal swellings such as globules and spheroids are a distinct feature of axonopathy and our recent study showed that transgenic (tg) mice expressing DLB-linked P123H $\beta$-synuclein (P123H $\beta S$ ) were characterized by P123H $\beta S$-immunoreactive axonal swellings (P123H $\beta$ S-globules). Therefore, the objectives of this study were to evaluate a-synuclein (aS)-immunoreactive axonal swellings (aS-globules) in the brains of tg mice expressing human wild-type aS and to compare them with the globules in P123H $\beta$ S tg mice.

Results: In aS tg mice, aS-globules were formed in an age-dependent manner in various brain regions, including the thalamus and basal ganglia. These globules were composed of autophagosome-like membranous structures and were reminiscent of $\mathrm{P} 123 \mathrm{H} \beta S$-globules in $\mathrm{P} 123 \mathrm{H} \beta S$ tg mice. In the aS-globules, frequent clustering and deformation of mitochondria were observed. These changes were associated with oxidative stress, based on staining of nitrated aS and 4-hydroxy-2-nonenal (4-HNE). In accord with the absence of mitochondria in the P123H BS-globules, staining of nitrated aS and 4-HNE in these globules was weaker than that for aS-globules. Leucine-rich repeat kinase 2 (LRRK2), the PARK8 of familial PD, was detected exclusively in aS-globules, suggesting a specific role of this molecule in these globules.

Conclusions: Lysosomal pathology was similarly observed for both aS- and P123H $\beta S$-globules, while oxidative stress was associated with the aS-globules, and to a lesser extent with the P123H $\beta S$-globules. Other pathologies, such as mitochondrial alteration and LRRK2 accumulation, were exclusively detected for aS-globules. Collectively, both aS- and P123H BS-globules were formed through similar but distinct pathogenic mechanisms. Our findings suggest that synuclein family members might contribute to diverse axonal pathologies.
\end{abstract}

Keywords: a-synuclein, P123H $\beta$-synuclein, Parkinson's disease, Mitochondria, Lysosome, Transgenic mouse

\footnotetext{
*Correspondence: hashimoto-mk@igakuken.or.jp

${ }^{1}$ Division of Sensory and Motor Systems, Tokyo Metropolitan Institute of Medical Science, Tokyo 156-8506, Japan

Full list of author information is available at the end of the article
} 


\section{Background}

$\alpha$-Synucleinopathies such as Parkinson's disease (PD) and dementia with Lewy bodies (DLB) are leading causes of movement disorders and dementia in aging populations [1,2]. $\alpha$-Synucleinopathies are characterized by the presence of Lewy bodies and Lewy neurites, which are filled with aggregates of $\alpha$-synuclein $(\alpha \mathrm{S})$, an abundant nerve terminal protein with unknown functions. It is well established that $\alpha \mathrm{S}$ has a central role in the pathogenesis of these diseases, but little is known about the onset and progression of the degenerative process.

Recently, evidence has accumulated to indicate that an axonal pathology caused by $\alpha \mathrm{S}$ may play a critical role in the early pathogenesis of $\alpha$-synucleinopathies. This is supported by the widespread axonal pathology observed from the earliest stages of these disorders, suggesting that axonal function may be impaired in the early pathogenesis [3]. In this context, the appearance of $\alpha \mathrm{S}$-positive Lewy neurites has been shown to precede that of Lewy bodies in brains and cardiac sympathetic neurons. These results suggest that degeneration begins in the distal axon and proceeds towards the cell body in $\alpha$-synucleinopathies $[4,5]$. Thus, elucidation of the mechanisms of axonal pathology is important to gain a better understanding of the early pathogenesis of $\alpha$-synucleinopathies and to establish effective therapeutic agents.

Axonal pathologies such as axonal deposits of $\alpha \mathrm{S}$ and axonal swellings have been shown in various lines of transgenic (tg) mice expressing either wild-type $\alpha \mathrm{S}$ or $\beta S$ with PD-linked missense mutations [6-9], but have not been characterized extensively. Furthermore, not only $\alpha S$, but also two $\alpha S$-related molecules, $\beta$-synuclein ( $\beta S$ ) and $\gamma$-synuclein $(\gamma S)$, are associated with neuritic pathology $[10,11]$, such as that in dystrophic neurites and spheroid structures, in the brain in synucleinopathies. Thus, it is unclear how the synuclein family of peptides is involved in the axonal pathogenesis. Based on our findings for formation of axonal swellings in tg mice expressing DLB-linked P123H $\beta$ S [12], we wondered if these swellings might be a useful model to investigate the axonal pathology caused by each synuclein protein. In this context, the objective of the present study was to characterize axonal swellings of tg mice expressing human $\alpha \mathrm{S}$ and to compare them with those found in P123H $\beta S$ tg mice. The results suggest that axonal swellings found in these two types of mice may be formed by similar but distinct mechanisms.

\section{Results}

\section{Age-dependent formation of aS-accumulated axonal} swellings (aS-globules) in brains of aS tg mice

To evaluate $\alpha \mathrm{S}$-induced axonal pathologies in the brains of $\alpha \mathrm{S}$ tg mice, various histological analyses were carried out. Hematoxylin and eosin staining showed no apparent changes (Figure 1a), but immunohistochemistry of brain sections of $\alpha \mathrm{S}$ tg mice, but not of their wild type littermates, exhibited formation of strongly $\alpha \mathrm{S}$ immunoreactive axonal swellings in various areas, including the basal ganglia, thalamus, midbrain and olfactory bulb, but not in the cortex and cerebellum (Figure 1, Additional file 1: Figure S1a). These swellings formed in an age-dependent manner, with the highest number occurring in old stage (Figure 1b). The $\alpha S$ immunoreactive swellings were occasionally immunopositive for heavy chain of kinesin as an axonal marker, but were not stained by eosin or anti-neurofilament- $\mathrm{L}$ antibody (Figure 1c), suggesting that they were a type of axonal swellings. In addition, the long-axis diameter of $\alpha$ S-immunoreactive swellings was $6.55 \pm 2.56 \mu \mathrm{m}$ (mean \pm S.D., $\mathrm{n}=30$ globules). Because the diameters of the swellings were less than $20 \mu \mathrm{m}$, they were categorized as "globules" (small spheroids). The swellings were not stained by Thioflavin $\mathrm{T}$ or Thiazine Red (data not shown) $[13,14]$, suggesting that fibrillation of accumulated $\alpha \mathrm{S}$ was not required for formation of $\alpha \mathrm{S}$-globules in brains of $\alpha \mathrm{S}$ tg mice.

The $\alpha$ S-globules were immunopositive for several GABAergic markers, including anti- $\gamma$-aminobutyric acid (GABA) and anti-glutamic acid decarboxylase (Additional file 2: Figure S2a), and negative for other neuronal markers such as vesicular glutamate transporter-1 or -2 , dopamine transporter, vesicular acetylcholine transporter and serotonin (data not shown). These results suggest that the $\alpha$ S-globules might be derived from GABAergic neurons. Furthermore, the $\alpha \mathrm{S}$-globules were highly immunopositive for calbindin D-28 k, but were partially positive for calretinin, and only occasionally positive for parvalbumin (Additional file 2: Figure S2b), suggesting that the globules might be derived from several types of GABAergic neurons. The mechanism through which globules caused by $\alpha \mathrm{S}$ are preferentially formed in GABAergic neurons is unclear. However, our results are consistent with previous studies showing that both dopaminergic neurons and other neuronal types, including large cholinergic interneurons and medium-sized GABAergic projection neurons, are involved in the neuritic pathology in the neostriatum of the PD brain.

\section{Lysosomal pathology of aS-globules in brains of aS tg mice} To investigate the ultrastructure of $\alpha S$-globules in brains of $\alpha \mathrm{S}$ tg mice, immunoelectron microscopy was performed (Figure 2). Similarly to the globules in P123H $\beta S$ tg mice [15], the $\alpha \mathrm{S}$-globules in $\alpha \mathrm{S}$ tg mice were characterized by membranous elements including autophagosome-like structures with double membranes (Figure 2a-e), multivesicular bodies (Figure 2b, e) and multilayered membranes (Figure $2 \mathrm{~d}$ ). These results suggest a possible relevance to aberrant regulation of the 
(a)
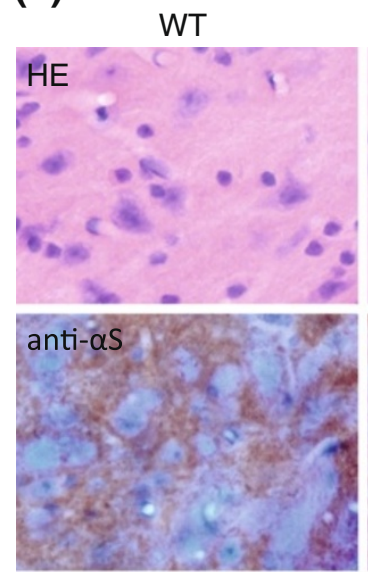

(c)
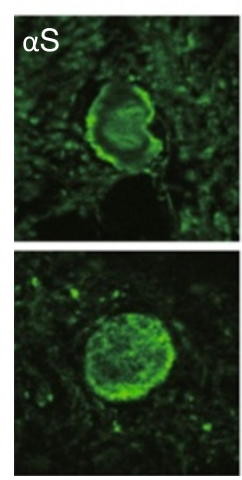

$\alpha S$
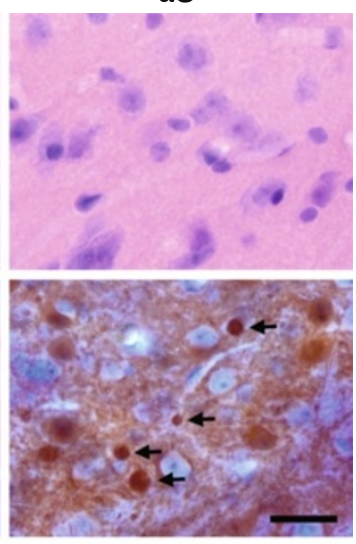

.
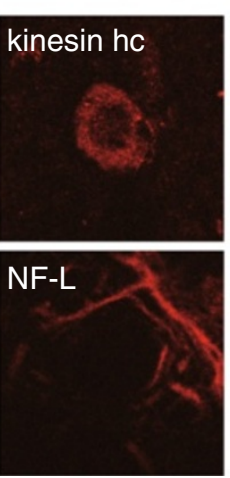

(b)

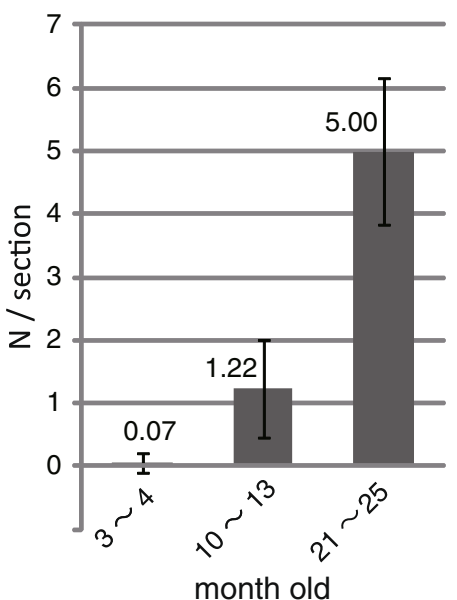

Figure 1 Age-dependent formation of aS-immunopositive axonal swellings (aS-globules) in brains of aS tg mice. (a) Hematoxylin and eosin staining (upper two panels) showed no apparent changes in brains of aS tg mice (right) and non-tg littermates (left). Immunohistochemistry of aS (lower two panels) showed formation of aS-globules (arrows) in aS tg mice (right), but not in wild type littermates (left). Representative images for the thalamus are shown. Scale bar $=20 \mu \mathrm{m}$. (b) Age-dependent formation of aS-globules in the aS tg brain detected by anti-aS antibody. The numbers of globules with diameters $>4 \mu \mathrm{m}$ were unbiasedly counted in the striatum of aS tg brains at three ages: young $(n=5,3-4 \mathrm{mo})$, adult $(n=3,10-13 \mathrm{mo})$, and old $(n=3,21-25 \mathrm{mo})$. (c) Double immunofluorescence was performed using aS as a globule identification. Kinesin heavy chain (kinesin hc) was positive (upper three panels) and neurofilament-light (NF-L) was negative (lower three panels). Representative images are shown for the pontine nuclei (upper) and striatum (lower). Scale bar $=5 \mu \mathrm{m}$.

autophagy-lysosomal system. Notably, unique membranous structures, comprised of alternating dense and light band forms with a periodicity of 5.8-6.1 nm units and an electron-dense line thickness of 3.3-3.6 nm units, were present in the $\alpha \mathrm{S}$-globules (Figure $2 \mathrm{i}, \mathrm{j}$ ). Moreover, the tubular inclusions (13- to 18-nm diameter) existed in the $\alpha \mathrm{S}$-globules (Figure 2f, h). These structures were reminiscent of the fingerprint profile [16] and curvilinear body [17] that are frequently associated with lysosomal storage diseases such as neuronal ceroid-lipofuscinosis and gangliosidosis. Neither such membranous structures nor Lewy body-like filamentous structures were observed in the somata of $\alpha \mathrm{S}$-expressing neurons.

To characterize the lysosomal pathology in the $\alpha \mathrm{S}$ globules in more detail, an immunofluorescence study was carried out. The globules were immunopositive not only for major gangliosides (GD1a and GM1) but also for some minor gangliosides (GD3, GM2 and GM3) [18,19] (Additional file 3: Figure S3). Based on our previous reports regarding the protective effects of gangliosides on lysosomal pathology in neuroblastoma cells expressing P123H ßS, we speculate that gangliosides might be protective against formation of globules. Finally, the activities of cathepsins B and -D were significantly decreased in $\alpha \mathrm{S}$ tg mice compared with non-tg littermates (The mean activity of cathepsin B was $69.8 \pm 14.2 \%$ and that of cathepsin D was $86.6 \pm 10.6 \%$ ) (Additional file 1: Figure S1, Additional file 4: Additional Methods). These results suggest, but do not prove, that autophagosome-like membranes might accumulate due to decreased clearance by lysosomes. Essentially similar results were previously observed in brains of $\mathrm{P} 123 \mathrm{H}$ ßS tg mice [15]. 

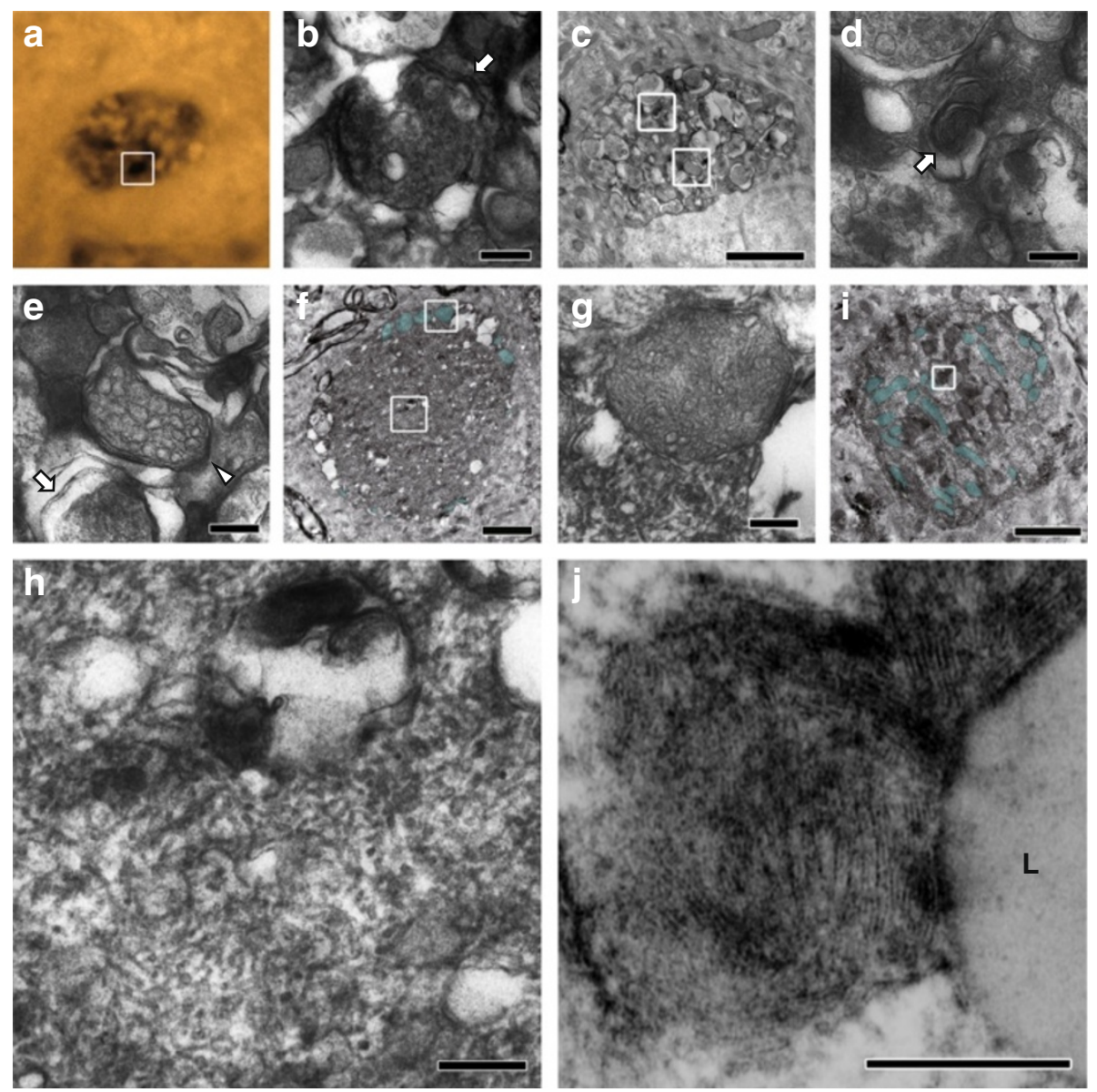

Figure 2 Ultrastructure of aS-globules in brains of aS tg mice. Immunoelectron microscopic analysis was performed using anti-aS. aS-immunopositive globules (a) were characterized by lysosomal pathologies such as an aS-immunopositive multivesicular body (b: arrow), autophagic vacuoles (c), myelinosome (d: arrow), a myelinoid membrane (e: arrow), and a light multivesicular body (e: arrow head). Formation of a fingerprint profile (j) adjacent to a lipid droplet $(\mathbf{j}$ : $\mathbf{L})$ and curvilinear bodies $(\mathbf{f}, \mathbf{h})$ are reminiscent of lysosome storage disease. Accumulation of mitochondria was also occasionally observed ( $\mathbf{f}$; $\mathbf{i}$; blue). Some mitochondria were swollen and deformed $(\mathbf{g})$. The globules are representatives of those in the thalamus $(\mathbf{a}-\mathbf{h})$ and striatum $(\mathbf{i}, \mathbf{j})$. The boxed area in panels with lower magnifications $(\mathbf{a}, \mathbf{c}, \mathbf{f}$, and $\mathbf{i})$ were enlarged in $\mathbf{b}$, and $\mathbf{j}$ or in two figures $(\mathbf{d}, \mathbf{e}, \mathbf{g}, \mathbf{h})$. Scale bar $=2 \mu \mathrm{m}$ for $\mathbf{c}, \mathbf{f}, \mathbf{i} ; 200 \mathrm{~nm}$ for $\mathbf{b}, \mathbf{d}, \mathbf{e}, \mathbf{g}, \mathbf{h}, \mathbf{j}$.

Enhanced oxidative stress with mitochondrial abnormality in aS-globules in brains of aS tg mice

Besides a lysosomal pathology, immunoelectron microscopy showed accumulation of mitochondria in $\alpha S$ globules in brains of $\alpha S$ tg mice. Some $\alpha S$-globules displayed clustering of mitochondria (Figure 2f, i), while others had swollen mitochondria in the peripheral regions of the globules (Figure 2g). Consistent with the deformation of the mitochondria, there was a clear decrease in their osmophility (Figure $2 \mathrm{~g}$ ), indicating increased $\mathrm{pH}$ in the intermembrane space of mitochondria. However, more severe mitochondrial pathologies, such as distorted and vacuolated mitochondria, were not observed.

To characterize the mitochondrial pathology in the $\alpha \mathrm{S}$ globules, an immunofluorescence study was conducted. The results showed that $\alpha \mathrm{S}$-globules were immunopositive for various mitochondria markers, including voltage- dependent anion channel isoform 1 (VDAC1), cytochrome $\mathrm{C}$ and the stress protein heat shock protein 60 (HSP 60) (Figure 3). All VDAC1 immunohistochemical images in $\alpha \mathrm{S}$-globules showed a diffuse pattern (67\% in the thalamus, $\mathrm{n}=12$ ). This pattern of VDAC1 staining suggested possible damage of mitochondrial outer membrane [20]. However, it is unlikely that apoptosis was involved since cytochrome C and HSP 60 staining was still localized in the swollen mitochondria. The absence of COX IV, a cytochrome C oxidase subunit in the mitochondrial inner membrane, in the $\alpha \mathrm{S}$-globules is consistent with a report showing that genes derived from mitochondrial DNA, including COX IV, are deleted in many cases of sporadic PD [21].

Abnormal accumulation of mitochondria in $\alpha$ S-globules might stimulate oxidative stress. This possibility was assessed based on immunoreactivities to nitrated $\alpha S$ 


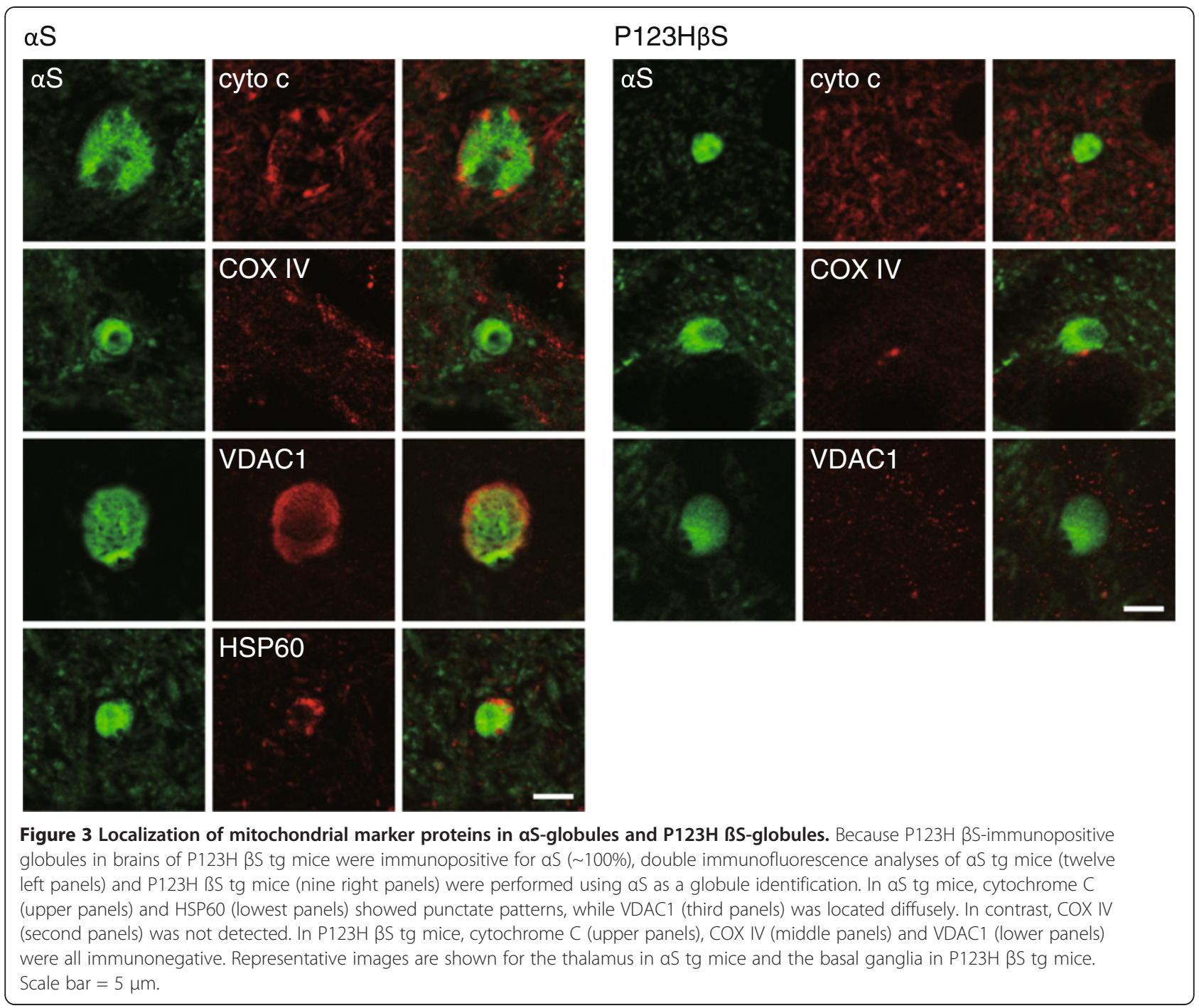

and 4-hydroxy-2-nonenal (4-HNE), a product of biological lipid peroxidation (Figure 4) [22,23]. In support of this hypothesis, considerable amounts of the $\alpha S$ globules were immunostained with anti-nitrated- $\alpha \mathrm{S}$ antibody $(\sim 61 \%$ in the basal ganglia, $n=59)$, suggesting that nitration was upregulated (Figure 4). Similarly, the $\alpha \mathrm{S}$-globules had the immunoreactivity for anti-4HNE antibody $(\sim 43 \%$ in the basal ganglia, $\mathrm{n}=54)$, confirmed that the oxidative stress was increased in the $\alpha$ S-globules (Figure 4). Phosphorylation of $\alpha \mathrm{S}$ was evaluated as another possible posttranslational modification, since Lewy bodies in human brains are consistently immunopositive with anti-phospho- $\alpha \mathrm{S}$ antibody $[22,23]$. In $\alpha S$ tg mice, many but not all of the $\alpha S$ globules were stained with anti-phospho- $\alpha \mathrm{S}$ antibody $(\sim 62 \%$ in the basal ganglia, $\mathrm{n}=63)$, indicating that phosphorylation of $\alpha S$ may not be critical for globule formation.

\section{Oxidative stress without mitochondria in $\mathrm{P} 123 \mathrm{H}$}

BS-globules in brains of $\mathrm{P} 123 \mathrm{H}$ BS tg mice

In contrast to the $\alpha \mathrm{S}$-globules, our previous ultrastructural study showed that mitochondria were rarely observed in $\mathrm{P} 123 \mathrm{H}$ ßS-globules in brains of $\mathrm{P} 123 \mathrm{H} ß \mathrm{~S}$ tg mice [15]. Similarly to the results in $\alpha \mathrm{S}$ tg mice, $\mathrm{P} 123 \mathrm{H}$ ßS tg mice had $\mathrm{P} 123 \mathrm{H}$ ßS-immunopositive swellings (P123H ßS-globules) derived from GABAergic projection neurons which were immunoreactive for calbindin D-28 k, but were negative for both calretinin and parvalbumin [15]. We observed that the long-axis diameter of P123H ßS-globules $(5.70 \pm 1.15 \mu \mathrm{m}$, mean \pm S.D., $\mathrm{n}=$ 30 globules) was comparable to that of $\alpha S$-globules $(6.55 \pm 2.56 \mu \mathrm{m} . \mathrm{p}=0.10$, Student's $t$-test). Staining for VDAC1, cytochrome $\mathrm{C}$ and COX IV was negative in $\mathrm{P} 123 \mathrm{H}$ ßS-globules in brains of $\mathrm{P} 123 \mathrm{H}$ ßS tg mice (Figure 3). In accord with the absence of mitochondria, oxidative stress, as assessed by anti-4HNE antibody, in 


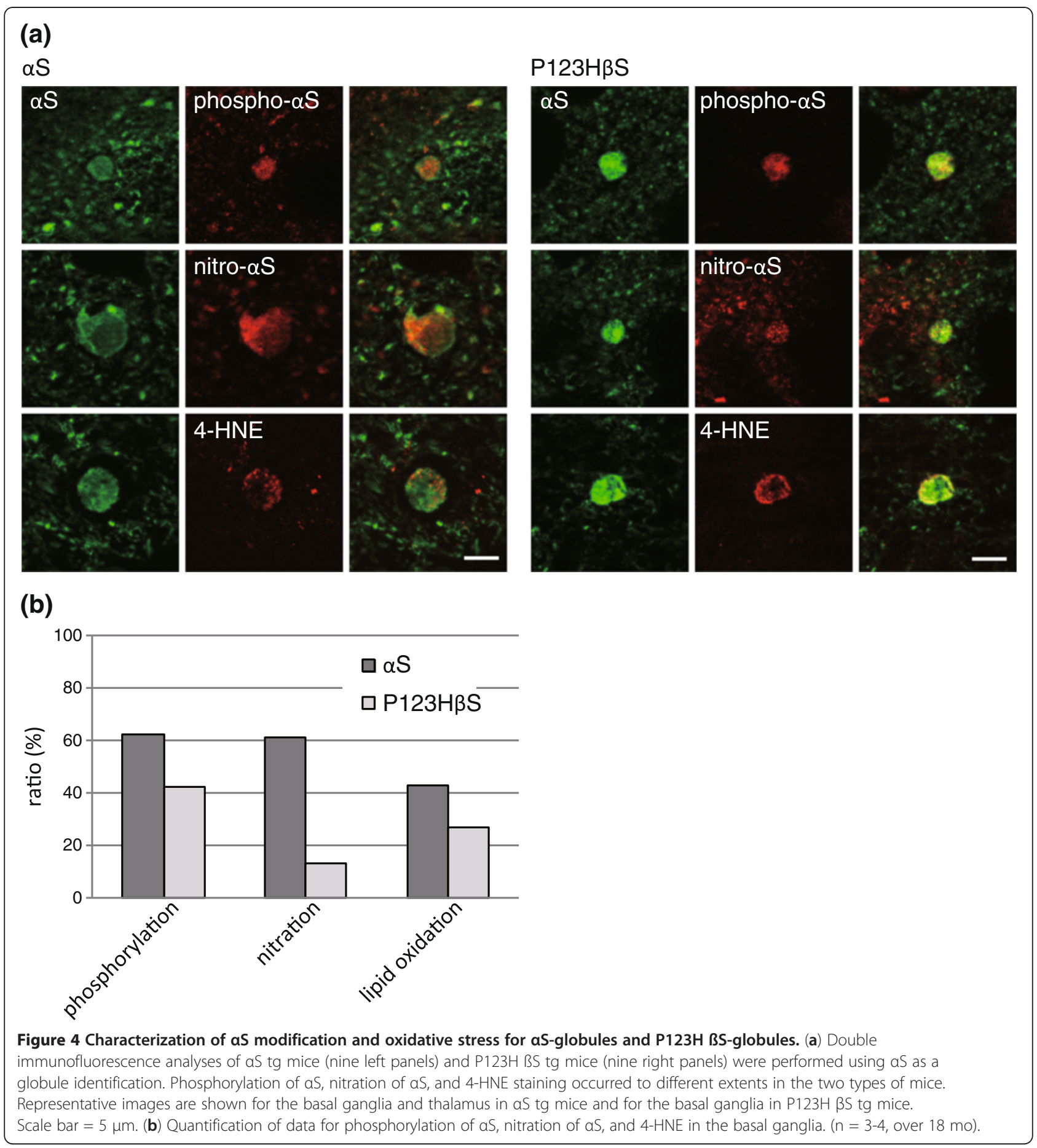

$\mathrm{P} 123 \mathrm{H}$ ßS-globules in $\mathrm{P} 123 \mathrm{H}$ ßS tg mice was less than that in $\alpha \mathrm{S}$ tg mice $(\sim 27 \%$ in the basal ganglia, $\mathrm{n}=55)$ (Figure 4). In a similar fashion, nitration of endogenous mouse $\alpha \mathrm{S}$ in $\mathrm{P} 123 \mathrm{H}$ ßS-globules was negligible $(\sim 13 \%$ in the basal ganglia, $\mathrm{n}=54$ ) (Figure 4 ), while phosphorylation of endogenous mouse $\alpha \mathrm{S}$ in $\mathrm{P} 123 \mathrm{H}$ ßSglobules was similar to that in $\alpha \mathrm{S}$-globules in the basal ganglia of $\alpha \mathrm{S}$ tg mice $(\sim 42 \%$ in the basal ganglia, $\mathrm{n}=55)$ (Figure 4).

The mechanism through which $\mathrm{P} 123 \mathrm{H} \beta \mathrm{S}$ stimulates formation of globules in the absence of mitochondria in axonal degeneration is unclear. We hypothesized that cholesterol might play a role in the pathogenesis, based on the results of immunoelectron microscopy for $\mathrm{P} 123 \mathrm{H}$ 
ßS-globules in brains of $\mathrm{P} 123 \mathrm{H} ß \mathrm{~S}$ tg mice, in which approximately half of the globules had accumulation of lipids droplets (Figure 5a). As we expected, cholesterol detection by Schultz staining was highly positive in globules in brains of $\mathrm{P} 123 \mathrm{H} ß \mathrm{~S}$ tg mice (Figure $5 \mathrm{~b}$ ). In contrast, no staining of cholesterol was observed in globules in brains of $\alpha \mathrm{S} \operatorname{tg}$ mice.

\section{Analysis of familial PD-risk factors in globule formation}

Since many familial PD risk factors [24,25] have been implicated in disorders of subcellular organelles such as lysosomes and mitochondria, we examined whether any of these factors were involved in globule formation in $\alpha \mathrm{S}$ tg mice or P123H $3 S$ tg mice. Notably, an immunofluorescence study showed frequent detection of leucine-rich repeat kinase 2 (LRRK2) (PARK8) in $\alpha$ S-globules $(\sim 79 \%$ in the thalamus, $\mathrm{n}=28$ ) (Figure 6a). The staining exhibited a small granular dot pattern, suggesting that LRRK2 might be associated with the membranous structures. The specificity of staining was confirmed by preabsorption of the antibody with the immunogen peptides. In contrast, immunoreactivity of LRRK2 was not observed for $\mathrm{P} 123 \mathrm{H}$ ßS-globules in the basal ganglia of $\mathrm{P} 123 \mathrm{H} 3 \mathrm{~S}$ tg mice (Figure 6b). It is intriguing if absence of LRRK2 in P123H ßS globule might reflect that LRRK2 strictly differentiates human $\alpha \mathrm{S}$ from mouse $\alpha S$ and human $\mathrm{P} 123 \mathrm{H} ß \mathrm{~S}$. Alternative possibility to explain the differential expression of LRRK2 between the $\alpha \mathrm{S}$ globule and $\mathrm{P} 123 \mathrm{H}$ ßS globule is that LRRK2 might associate with some specific molecules which are expressed only in the $\alpha \mathrm{S}$ globule. In this regard, rab5b could be such a candidate since a recent study has well characterized this molecule as a binding partner of LRRK2 [26]. Our immunofluorescence study showed that LRRK2 associates with an endosome molecule Rab5B in axon terminals with a normal range of size, but Rab5B was not detected in the $\alpha \mathrm{S}$-globules (Figure $6 \mathrm{c}$ ). This result suggests a possibility that LRRK2 have lost the ability to interact with Rab5B, contributing to endosomal deficits during globule formation. Furthermore, although previous reports showed that LRRK2 associated various organelles, such as mitochondria and lysosome [26,27], we did not observed interaction of LRRK2 with mitochondria markers in the $\alpha \mathrm{S}$-globules (data not shown).

Furthermore, despite the accumulation of LRRK2 in the $\alpha S$-globules, immunoblot analysis $[28,29]$ failed to detect an apparent difference in LRRK2 bands among brain extracts derived from $\alpha \mathrm{S}$ tg mice, $\mathrm{P} 123 \mathrm{H}$ ßS tg mice, and their wild type littermates (data not shown), possibly due to the relatively small amount of LRRK2 in the $\alpha$ S-globules compared to total LRRK2 in the whole brain.

It has been well characterized that Parkin (PARK2) and PTEN-induced putative kinase 1 (PINK1) (PARK6) are autosomal recessive factors that are critically involved in the maintenance of mitochondrial quality, and that mutations in these genes are causative for mitophagy. However, neither Parkin nor PINK1 was immunopositive in $\alpha \mathrm{S}$ - and $\mathrm{P} 123 \mathrm{H} ß \mathrm{~S}$-globules (Figure 6a). In addition, there was no immunoreactivity for DJ-1 (PARK7) in both types of globules (Figure 6a).

\section{Discussion}

Axonal swellings, including globules and spheroids, are characteristic features of axonopathies observed in a number of diseases, including ischemia, trauma, neuroaxonal dystrophy, neurodegenerative disorders, as well as in aging. A recent study suggested that dysfunction of the autophagy-lysosome pathway could be one major contributor to axonal swellings [30,31]. Failure to (a)

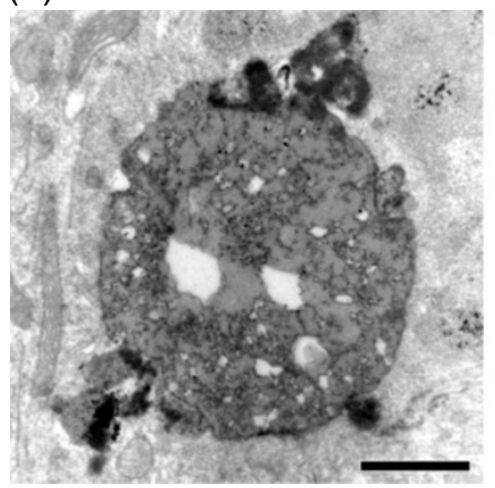

(b)

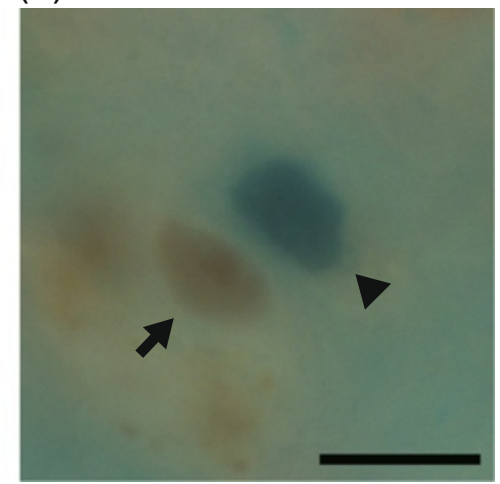

Figure 5 Positive staining of cholesterol in P123H $\mathbf{B S}$ tg mice. (a) An immunoelectron micrograph of aS-immunopositive globules in the basal ganglia of $\mathrm{P} 123 \mathrm{H} \beta \mathrm{S}$ tg mice showed many lipid droplets. Scale bar $=1 \mu \mathrm{m}$. (b) Detection of cholesterol in the basal ganglia of $\mathrm{P} 123 \mathrm{H} \beta \mathrm{S}$ tg mice was performed by Schultz staining. The arrowhead shows cholesterol-positive structure (blue), while the arrow indicates soma containing other lipids (brown). Scale bar $=10 \mu \mathrm{m}$. 
(a) $\alpha S$
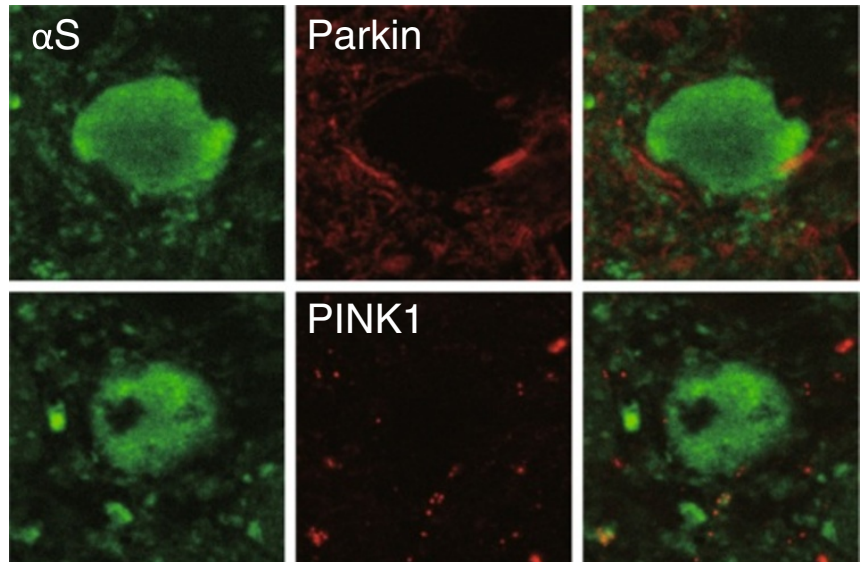

\section{PINK1}
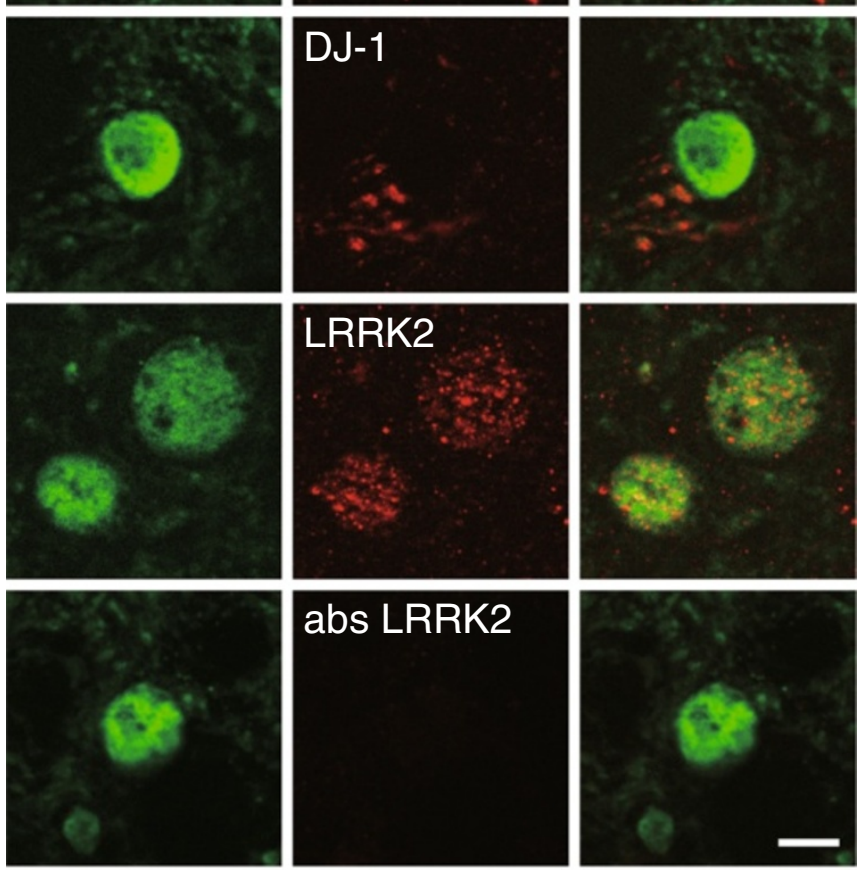

(b) $\mathrm{P} 123 \mathrm{H} \beta \mathrm{S}$
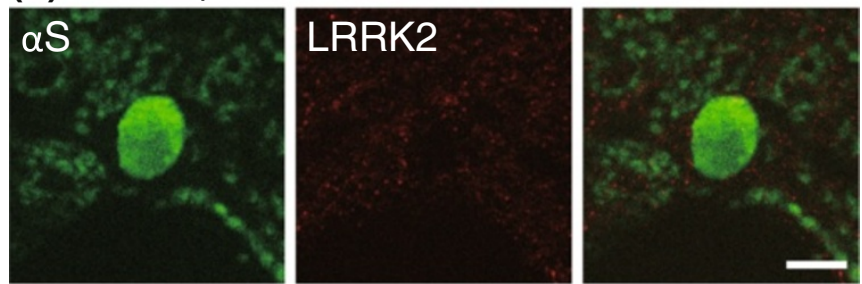

(c) $\alpha S$
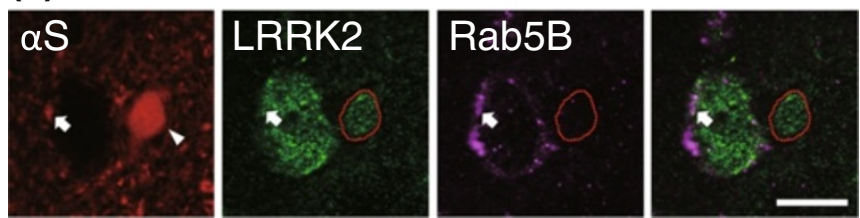

Figure 6 (See legend on next page.) 
(See figure on previous page.)

Figure 6 LRRK2 accumulates in globules in aS tg mice. (a and $\mathbf{b}$ ) Double immunofluorescence for aS with parkin, PINK1, DJ-1, LRRK2, or negative control (the immunopeptide-preabsorbed anti-LRRK2 antibody) in aS tg mice (a) and P123H BS tg mice (b). Note that aS-globules were immunopositive for LRRK2 ( 79\%, $\mathrm{n}=22)$, whereas P123H BS globules were negative for LRRK2. Representative images are shown for the thalamus (aS) and basal ganglia (P123H BS). Scale bar = $5 \mu \mathrm{m}$ for all panels. (c) Triple immunofluorescence for aS, LRRK2 and Rab5B for basal ganglia in aS tg mice. LRRK2 and Rab5B were colocalized in axon terminal (arrow), but were not colocalized in the aS-globule (arrowhead) Scale bar $=10 \mu \mathrm{m}$ for all panels.

degrade subcellular materials or organelles at distal axons and/or nerve terminals or failure to export these materials by axonal transport has been shown to produce swollen nerve terminals. Such a mechanism might be involved in formation of $\alpha \mathrm{S}$ - and $\mathrm{P} 123 \mathrm{H} \beta S$-globules. In the present study, $\alpha S$-globules in brains of $\alpha S$ tg mice were characterized by autophagosome-like membranous elements and were immunopositive for various minor gangliosides, which is reminiscent of some types of lysosomal storage disease. Consistent with this, lysosomal activity, as assessed by the activities of cathepsins B and $-D$, was significantly decreased in brain extracts of $\alpha \mathrm{S}$ tg mice compared with those from non-tg littermates. Similar lysosomal dysfunctions were previously observed for $\mathrm{P} 123 \mathrm{H} \beta S$-globules in brains of $\mathrm{P} 123 \mathrm{H} \beta \mathrm{S}$ tg mice. Taken together, these results suggest that downregulation of the lysosome degradation pathway may be a common mechanism leading to globule formation in $\alpha \mathrm{S}$ and $\mathrm{P} 123 \mathrm{H} \beta \mathrm{S}$ tg mice.

In contrast to the lysosomal pathology, mitochondria accumulated specifically in $\alpha S$-globules. To the best of our knowledge, only one study has previously described abnormal mitochondria in the axonal pathology in tg mice expressing prion promoter-driven $\alpha S$ [32]. In agreement with this study, immunoelectron microscopy of $\alpha \mathrm{S}$ revealed abnormal accumulation of mitochondria in $\alpha \mathrm{S}$-globules. Some $\alpha \mathrm{S}$-globules displayed clustering of mitochondria, while others had swollen mitochondria in the peripheral regions. Immunoreactivities of mitochondrial markers such as VDAC1 and cytochrome $\mathrm{C}$ were also found in $\alpha \mathrm{S}$-globules. These results suggest that mitochondria clustering might become hyperactive in response to lysosomal dysfunction. Consistent with these findings, $\alpha \mathrm{S}$-globules were associated with oxidative stress, as assessed by staining of 4-HNE and nitrated $\alpha \mathrm{S}$. Conversely, no evidence of mitochondria was obtained in $\mathrm{P} 123 \mathrm{H}$ BS-globules, hence oxidative stress (assessed by 4 -HNE staining) was less than that in $\alpha S$-globules. The mechanism through which $\mathrm{P} 123 \mathrm{H}$ BS causes mild level of oxidative stress without mitochondria is unclear, but it is noteworthy that cholesterol staining was positive in P123H $\beta S$-globules but not in $\alpha \mathrm{S}$-globules. Given that cholesterol and its metabolites are implicated in oxidative stress in the pathogenesis of neurodegenerative diseases [33], the increased oxidative stress in $\mathrm{P} 123 \mathrm{H}$ $\beta S$-globules could be partly due to accumulation of cholesterol. A further study is warranted to test this intriguing possibility.

LRRK2 was found to be located in $\alpha \mathrm{S}$-globules and may be actively involved in the axonal pathology. Indeed, it was previously shown that LRRK2 was crucial for regulation of neurite formation and length. Knockdown of LRRK2 led to long, highly branched neuritic processes, whereas constructs with increased kinase activity exhibited short simple processes in neuronal cultures (or transduced nigrostriatal models) [34]. More recently, LRRK2R1441G BAC tg mice were shown to have various characteristic axonal pathologies, including large tyrosine hydroxylase-positive spheroid-like structures, dystrophic neurites and enlarged axonal endings [35]. Although the mechanisms are still unclear, the specific accumulation of LRRK2 in $\alpha \mathrm{S}$-globules naturally leads to the speculation that LRRK2 may cooperate with $\alpha \mathrm{S}$ in the axonal pathology. In support of this possibility, both $\alpha \mathrm{S}$ and LRRK2 have been shown to be commonly involved in pathologies such as impairment of cytoskeleton dynamics and dysregulation of the protein degradation system. Moreover, it was recently shown that various neuropathological features of A53T $\alpha \mathrm{S}$ tg mice, such as impaired microtubule dynamics, Golgi disorganization, and decreased proteasomal activity, were worsened by cross-breeding with LRRK2 $\mathrm{tg}$ mice, but ameliorated by genetic ablation of LRRK2 [36]. Further investigation is required to determine whether $\alpha \mathrm{S}$ and LRRK2 cooperate with each other to produce diverse pathologies, including axonal degeneration.

Finally, given that $\mathrm{P} 123 \mathrm{H} \beta \mathrm{S}$ may represent a rare familial case of DLB, it is important to consider whether wild type $\beta S$ has any role in the formation of axonal globules in sporadic cases of $\alpha$-synucleinopathies. In this context, neurite accumulation of $\beta S$ has been demonstrated in various synucleinopathies, including PD, DLB, and neurodegeneration with brain iron accumulation, type I. Although wild type $\beta S$ is neuroprotective, this molecule might become pathogenic during aging. It is also possible that wild type $\beta S$ might become pathogenic under certain extreme conditions or through the action of specific environmental factors, leading to stimulation of globule formation. Thus, it is an intriguing possibility that the synuclein family of peptides might contribute to the formation of diverse axonal pathologies. 


\section{Conclusions}

The main objectives of this study were to evaluate $\alpha \mathrm{S}$-globules in the brains of $\mathrm{tg}$ mice expressing human wild-type $\alpha S$ and to compare them with the $\mathrm{P} 123 \mathrm{H} \beta \mathrm{S}$-globules in $\mathrm{P} 123 \mathrm{H} \beta \mathrm{S}$ tg mice. The results showed lysosomal pathology was similarly observed for both $\alpha \mathrm{S}$ - and $\mathrm{P} 123 \mathrm{H} \beta \mathrm{S}$-globules. Oxidative stress was associated with the $\alpha \mathrm{S}$-globules, and to a lesser extent with the $\mathrm{P} 123 \mathrm{H} \beta \mathrm{S}$-globules. Other pathologies, such as mitochondrial alteration and LRRK2 accumulation, were exclusively detected for $\alpha \mathrm{S}$-globules. Together, both $\alpha \mathrm{S}$ - and P123H $\beta S$-globules were formed through similar but distinct pathogenic mechanisms, suggesting that synuclein family members might contribute to diverse axonal pathologies.

\section{Methods}

All animal procedures were approved and conducted in accordance with the regulations of the Animal Ethics Review Committee of Tokyo Metropolitan Institute of Medical Sciences. Thy1- $\alpha \mathrm{S}$ tg mice [37] and Thy1$\mathrm{P} 123 \mathrm{H} \beta \mathrm{S}$ tg mice (line C) [15] were analyzed using various histological procedures.

\section{Histology and immunohistochemistry Tissue preparation}

The mice were anesthetized by overdose of pentobarbital and sacrificed by cardiac perfusion using $5 \mathrm{ml}$ of an icecold solution of $250 \mathrm{mM}$ sucrose and $5 \mathrm{mM} \mathrm{MgCl}_{2}$ in $0.02 \mathrm{M}$ phosphate buffer ( $\mathrm{pH} 7.4$ ) (PB), followed by treatment with $4 \%$ paraformaldehyde, $15 \%$ saturated picric acid and $0.05 \%$ (for single or double-immunohistochemistry, and histochemistry), $0.5 \%$ (for immunoelectron microscopic analysis) or 1\% (for GABA immunohistochemistry) glutaraldehyde in $0.1 \mathrm{M} \mathrm{PB}$. Serial sections of 20 - or $50-\mu \mathrm{m}$ thickness were then prepared by a vibrating blade microtome (VT1200S; Leica, Nussloch, Germany). Tissue sections were put in glass tubes containing 15\% sucrose in $0.1 \mathrm{M} \mathrm{PB}$ for $3 \mathrm{~h}$, in $30 \%$ sucrose in $0.1 \mathrm{M} \mathrm{PB}$ for $3 \mathrm{~h}$, and kept at $-30^{\circ} \mathrm{C}$ until use [38].

\section{Hematoxylin and eosin staining}

Sections were stained with Mayer's haematoxylin and $0.5 \%$ eosin. Sections were imaged using a Carl Zeiss (Jena, Germany) microscope.

\section{Antisera}

All antisera or monoclonal antibodies were purchased from commercial sources (Table 1).

\section{Immunohistochemistry}

The sections were incubated in Tris-buffered saline (TBS) containing $1 \%$ sodium borohydrate for $30 \mathrm{~min}$, in addition to treatment with TBS containing $1 \% \mathrm{H}_{2} \mathrm{O}_{2}$ for
$30 \mathrm{~min}$ in the case of diaminobenzidine staining. They were then incubated with primary antibodies (listed in Table 1) in PBS containing 1\% normal horse serum and $0.4 \%$ Triton $\mathrm{X}-100$ (except that for the lipids detection) overnight at $4^{\circ} \mathrm{C}$, followed by detection with biotinylated secondary antibodies and an avidin-biotin complex kit (Vector Laboratories, Burlingame, CA) [39]. A positive reaction was detected using diaminobenzidine tetrahydrochloride (DAB) containing $0.01 \%$ hydrogen peroxide and counterstaining with hematoxylin. For detection with fluorescent dye, the sections were incubated with primary antibodies, followed by Alexa Fluorconjugated secondary antibodies (Invitrogen, Carlsbad, CA). The sections were observed using a sectioning fluorescence microscopy system (Apotome; Carl Zeiss, Jena, Germany).

\section{Immunoelectron microscopy}

The sections were incubated in PB containing 1\% sodium borohydrate for $30 \mathrm{~min}$ and in TBS containing 1\% $\mathrm{H}_{2} \mathrm{O}_{2}$ for 30 min before incubation with primary antiserum against $\alpha \mathrm{S}$ in TBS containing 10\% normal goat serum and $2 \%$ bovine serum albumin overnight at $4{ }^{\circ} \mathrm{C}$. The sections were then incubated in biotin-conjugated secondary antiserum followed by treatment with $\mathrm{ABC}$ complex (Vector Laboratories) and staining with nickelenhanced DAB. The stained sections were postfixed in $1 \% \mathrm{OsO}_{4}$ in $0.1 \mathrm{M} \mathrm{PB}$ for $60 \mathrm{~min}$, and then stained with $1 \%$ uranyl acetate and dehydrated in graded ethanol. Sections were flat embedded on silicon-coated glass slides in Quetol 812 (Nisshin EM, Tokyo, Japan). Immunopositive tissues were serially sectioned at 70-nm thickness with EM UC7 (Leica), followed by final staining with lead citrate. The labeled $\alpha \mathrm{S}$-globules were photographed using an H-7650 electron microscope (Hitachi, Tokyo, Japan) and image files were made from EM films using a scanner (GT-X970; Epson, Suwa, Japan) [38].

\section{Cholesterol staining}

The sections were incubated in $2.5 \%$ iron alum solution for 3 days at room temperature. Sections were onto slides, followed by draining the solution and drying. Schultz reagent (mixture of equal parts of glacial acetic acid and concentrated sulfuric acid) was applied onto the slide, and then a glass coverslip was mounted [40]. Sections were imaged using an Olympus (Tokyo, Japan) microscope.

\section{Globule counting}

For the caudate and putamen, sagittal sections approximately 1.3-1.9 lateral to the midline were used. The location of the slice and identification of brain regions were determined by comparison to atlas images, as previously described [15]. Fluorescent labeled $\alpha$ S-immunopositive 
Table 1 Primary and secondary antisera used in this study

\begin{tabular}{|c|c|c|c|c|c|}
\hline & Antigen & Host & Dilution & Mono/polyclonal & Source \\
\hline \multicolumn{6}{|c|}{ Primary antisera and antibodies } \\
\hline \multirow[t]{3}{*}{1} & a-synuclein & mouse & 1:500 (for EM) & monoclonal & BD Biosciences (610787) \\
\hline & & & 1:1000 (for GABA FIHC) & & \\
\hline & & & $1: 2000$ & & \\
\hline 2 & a-synuclein & rabbit & $1: 50$ & polyclonal & Cell Signaling (\#2628) \\
\hline 3 & phosphorylated a-synuclein & mouse & $1: 2000$ & monoclonal & WAKO (pSyn\#64) \\
\hline 4 & nitrated a-synuclein & mouse & $1: 50$ & monoclonal & $\begin{array}{l}\text { Santa Cruz Biotechnology } \\
\text { (sc-32279) }\end{array}$ \\
\hline 5 & 4-hydroxy-2-nonenal & mouse & $1: 40$ & monoclonal & NOF Corporation (MHN-020P) \\
\hline 6 & Calbindin D-28 k & rabbit & $1: 5000$ & polyclonal & Swant (CB38) \\
\hline 7 & Parvalbumin & mouse & $1: 2000$ & monoclonal & Merck Millipore (MAB1572) \\
\hline 8 & Calretinin & rabbit & $1: 2000$ & polyclonal & Swant (7699/4) \\
\hline 9 & Glutamic acid decarboxylase & rabbit & $1: 2000$ & polyclonal & BIOMOL (GC3008) \\
\hline 10 & GABA & rabbit & $1: 2000$ & polyclonal & Sigma (A2052) \\
\hline 11 & kinesin, heavy chain & mouse & $1: 50$ & monoclonal & Merck Millipore (MAB1614) \\
\hline 12 & neurofilament-ilght & mouse & $1: 200$ & monoclonal & Sigma (N5139) \\
\hline 13 & GD1a & mouse & $1: 10$ & monoclonal & Seikagaku Corporation (GMR17) \\
\hline 14 & GD3 & mouse & $1: 10$ & monoclonal & Seikagaku Corporation (GMR19) \\
\hline 15 & GM2 & mouse & $1: 10$ & monoclonal & Seikagaku Corporation (GMB28) \\
\hline 16 & GM3 & mouse & $1: 10$ & monoclonal & Seikagaku Corporation (GMR6) \\
\hline 17 & VDAC1 & rabbit & $1: 40$ & polyclonal & Protein Tech (10866-1-AP) \\
\hline 18 & cytochrome c & mouse & $1: 200$ & monoclonal & BD Biosciences (556432) \\
\hline 19 & COX IV & rabbit & $1: 100$ & monoclonal & Cell Signaling (\#4850) \\
\hline 20 & HSP60 & rabbit & $1: 50$ & polyclonal & Novus (NB100-91819) \\
\hline 21 & Parkin & rabbit & $1: 100$ & polyclonal & Merck Millipore (AB9244) \\
\hline 22 & PINK1 & rabbit & $1: 50$ & polyclonal & Novus (NB600-973) \\
\hline 23 & DJ-1 & rabbit & $1: 50$ & polyclonal & abcam (ab74268) \\
\hline 24 & LRRK2 & rabbit & $1: 200$ & polyclonal & Novus (NB300-268) \\
\hline 25 & VGAT & guinea pig & 1:500 & polyclonal & Synaptic Systems (131004) \\
\hline 26 & Rab5B & goat & $1: 50$ & polyclonal & $\begin{array}{l}\text { Santa Cruz Biotechnology } \\
\text { (sc-26569) }\end{array}$ \\
\hline \multicolumn{6}{|c|}{ Fluorescein conjugated probe } \\
\hline 1 & $\begin{array}{l}\text { Alexa } 488 \text { conjugated cholera toxin } \\
\text { subunit B }\end{array}$ & & $0.5 \mu \mathrm{g} / \mathrm{ml}$ & & invitrogen (C-34775) \\
\hline \multicolumn{6}{|c|}{ Fluorescein conjugated secondary antisera } \\
\hline 1 & Alexa 488 conjugated anti-mouse lgG & goat & $1: 200$ & polyclonal & invitrogen (A-11029) \\
\hline 2 & Alexa 488 conjugated anti-rabbit lgG & goat & $1: 200$ & polyclonal & invitrogen (A-11034) \\
\hline 3 & Alexa 594 conjugated anti-mouse lgG & goat & $1: 200$ & polyclonal & invitrogen (A-11032) \\
\hline 4 & Alexa 594 conjugated anti-rabbit lgG & goat & $1: 200$ & polyclonal & invitrogen (A-11037) \\
\hline 5 & Alexa 488 conjugated anti-mouse lgM & goat & $1: 100$ & polyclonal & invitrogen (A-21042) \\
\hline 6 & Alexa 680 conjugated anti-goat lgG & donkey & $1: 100$ & polyclonal & invitrogen (A-21084) \\
\hline \multicolumn{6}{|c|}{ Biotinylated secondary antisera } \\
\hline 1 & biotinylated anti-mouse lgG & horse & $1: 200$ & polyclonal & Vector (BA-2000) \\
\hline
\end{tabular}


globules with a long axis $\geq 4 \mu \mathrm{m}$ were counted directly under a fluorescent microscope or from photomicrographs of sections.

\section{Statistical analysis}

Data are given as the means \pm S.D. Statistical analysis was performed using SPSS (SPSS Inc. Chicago, IL). T-test was used for confirmation of significant differences among WT or P123H $\beta S$ tg, and $\alpha \mathrm{S}$ tg mice, with $\mathrm{P}<0.05$ considered to indicate a significant difference.

\section{Additional files}

Additional file 1: Figure S1. Lysosome and proteasome activities in the brain extracts of aS tg mice. (a) aS-globules were detected in the olfactory bulb (arrow), but not in the cerebellum, of old aS tg mice (24 mo). Scale bar=2 mm (upper panel), $50 \mu \mathrm{m}$ (lower two panels). (b) Cathepsin B, -D and proteasome activities were measured (Additional file 4: Additional Methods). Activities of lysosome (cathepsins B and -D) were significantly lower $(p<0.05)$ in the olfactory bulb but not in the cerebellum in aS $\mathrm{tg}$ mice compared to the same areas in non-tg littermates (over $23 \mathrm{mo}$ ). In contrast, there were no significant difference in proteasome activities (Peptidyl-glutamyl peptide-hydrolyzing (PGPH) enzyme and chymotrypsin) between as tg mice and non-tg littermates (mean \pm S.D.; * $\mathrm{p}<0.05, \mathrm{n}=6$ per group).

Additional file 2: Figure S2. aS-globules are derived from GABAergic neurons. (a) aS-immunopositive globules in the striatum and thalamus of old aS tg mice (over $18 \mathrm{mo}$ ) were consistently immunopositive for GABA and glutamic acid decarboxylase (GAD), and were weakly immunopositive for vesicular GABA transporter (VGAT) (arrowhead). Scale bar=5 $\mu \mathrm{m}$. (b) Immunoreactivity for calbindin (CB) was consistently observed. Staining was partially positive for parvalbumin (PV) and rarely positive for calretinin (CR) in the thalamus. Scale bar $=5 \mu \mathrm{m}$

Additional file 3: Figure S3. Immunoreactivities of gangliosides in aS-globules of aS tg mice. (a) Double immunofluorescence analysis of aS tg mice was performed using aS as a globule identification. aS-immunopositive globules in the thalamus of old aS tg mice (25 mo) were positively stained with various anti-ganglioside antibodies. Scale bar $=5 \mu \mathrm{m}$. (b) Quantification of these data.

Additional file 4: Additional Methods. Measurement of lysosome and proteasome activity.

\section{Competing interests}

The authors declare no competing financial interests.

\section{Authors' contributions}

$A S, M F, K S, Y T$, and $E R$ performed the experiments. AS, TH, ARL, EM and $M H$ designed and analyzed the data. AS, ARL, EM and $M H$ wrote the paper. All authors have read and approved the manuscript.

\section{Acknowledgements}

We thank Dr. N. Hattori at the Juntendo University School of Medicine and Drs. H. Kawano, H. Okado, K. Watabe, M. Ichikawa and T. Uchihara at the Tokyo Metropolitan Institute of Medical Science for their continuous encouragements. We also thank staff in Center for Basic Technology Research, Tokyo Metropolitan Institute of Medical Science for the technical assistance. This work was supported in part by a grant-in-aid for Science Research on Innovative Areas ("Brain Environment") from the Ministry of Education, Culture, Sports, Science, and Technology, Japan (to MH), Novartis Foundation for Gerontological Research (to MH) and NIH grants, AG18440, AG022074, AG11385 and NS044233 (to EM).

\section{Author details}

'Division of Sensory and Motor Systems, Tokyo Metropolitan Institute of Medical Science, Tokyo 156-8506, Japan. '2Department of Neurology,
Juntendo University School of Medicine, 2-1-1 Hongo, Tokyo, Bunkyo 113-8421, Japan. ${ }^{3}$ Department of Neurosciences, University of California-San Diego, La Jolla, CA 92093-0624, USA. ${ }^{4}$ Department of Pediatrics, and Cellular and Molecular Medicine, University of California-San Diego, La Jolla, CA 92093-0624, USA. ${ }^{5}$ Rady Children's Hospital, San Diego, CA 92193, USA.

Received: 11 June 2012 Accepted: 21 September 2012

Published: 26 September 2012

\section{References}

1. Trojanowski JQ, Goedert M, Iwatsubo T, Lee VM: Fatal attractions: abnormal protein aggregation and neuron death in Parkinson's disease and Lewy body dementia. Cell Death Differ 1998, 5:832-837.

2. Hashimoto M, Masliah E: Alpha-synuclein in Lewy body disease and Alzheimer's disease. Brain Pathol 1999, 9:707-720.

3. Braak H, Ghebremedhin E, Rub U, Bratzke H, Del Tredici K: Stages in the development of Parkinson's disease-related pathology. Cell Tissue Res 2004, 318:121-134

4. Braak H, de Vos RA, Bohl J, Del Tredici K: Gastric alpha-synuclein immunoreactive inclusions in Meissner's and Auerbach's plexuses in cases staged for Parkinson's disease-related brain pathology. Neurosci Lett 2006, 396:67-72

5. Orimo S, Uchihara T, Nakamura A, Mori F, Kakita A, Wakabayashi K Takahashi H: Axonal alpha-synuclein aggregates herald centripetal degeneration of cardiac sympathetic nerve in Parkinson's disease. Brain 2008, 131:642-650.

6. Masliah E, Rockenstein E, Veinbergs I, Mallory M, Hashimoto M, Takeda A, Sagara Y, Sisk A, Mucke L: Dopaminergic loss and inclusion body formation in alpha-synuclein mice: implications for neurodegenerative disorders. Science 2000, 287:1265-1269.

7. van der Putten $\mathrm{H}$, Wiederhold KH, Probst A, Barbieri S, Mistl C, Danner S, Kauffmann S, Hofele K, Spooren WP, Ruegg MA, et al: Neuropathology in mice expressing human alpha-synuclein. The Journal of neuroscience: the official journal of the Society for Neuroscience 2000, 20:6021-6029.

8. Giasson BI, Duda JE, Quinn SM, Zhang B, Trojanowski JQ, Lee VM: Neuronal alpha-synucleinopathy with severe movement disorder in mice expressing A53T human alpha-synuclein. Neuron 2002, 34:521-533.

9. Lee MK, Stirling W, Xu Y, Xu X, Qui D, Mandir AS, Dawson TM, Copeland NG, Jenkins NA, Price DL: Human alpha-synuclein-harboring familial Parkinson's disease-linked Ala-53 -> Thr mutation causes neurodegenerative disease with alpha-synuclein aggregation in transgenic mice. Proc Natl Acad Sci USA 2002, 99:8968-8973.

10. Galvin JE, Uryu K, Lee VM, Trojanowski JQ: Axon pathology in Parkinson's disease and Lewy body dementia hippocampus contains alpha-, betaand gamma-synuclein. Proc Natl Acad Sci USA 1999, 96:13450-13455

11. Galvin JE, Giasson B, Hurtig HI, Lee VM, Trojanowski JQ: Neurodegeneration with brain iron accumulation, type 1 is characterized by alpha-, beta-, and gamma-synuclein neuropathology. Am J Pathol 2000, 157:361-368.

12. Hashimoto M, La Spada AR: $\beta$-synuclein in the pathogenesis of Parkinson's disease and related a-synucleinopathies: emerging roles and new directions. Future Neurology 2012, 7:155-163.

13. Sakamoto M, Uchihara T, Hayashi M, Nakamura A, Kikuchi E, Mizutani T, Mizusawa H, Hirai S: Heterogeneity of nigral and cortical Lewy bodies differentiated by amplified triple-labeling for alpha-synuclein, ubiquitin, and thiazin red. Exp Neurol 2002, 177:88-94

14. Kanazawa T, Adachi E, Orimo S, Nakamura A, Mizusawa H, Uchihara T: Pale neurites, premature alpha-synuclein aggregates with centripetal extension from axon collaterals. Brain Pathol 2012, 22:67-78.

15. Fujita M, Sugama S, Sekiyama K, Sekigawa A, Tsukui T, Nakai M, Waragai M, Takenouchi T, Takamatsu Y, Wei J, et al: A beta-synuclein mutation linked to dementia produces neurodegeneration when expressed in mouse brain. Nat Commun 2010, 1:110.

16. Iseki E, Amano N, Yokoi S, Yamada Y, Suzuki K, Yazaki M: A case of adult neuronal ceroid-lipofuscinosis with the appearance of membranous cytoplasmic bodies localized in the spinal anterior horn. Acta Neuropathol 1987, 72:362-368

17. Kurokawa Y, Ueno T, Nakamura N, Kimura N: Deposits of neuronal ceroidlipofuscinosis in transitional structures-electron microscopic study. Folia Psychiatr Neurol Jpn 1985, 39:537-542. 
18. Kotani M, Kawashima I, Ozawa H, Terashima T, Tai T: Differential distribution of major gangliosides in rat central nervous system detected by specific monoclonal antibodies. Glycobiology 1993, 3:137-146.

19. Kotani M, Kawashima I, Ozawa H, Ogura K, Ishizuka I, Terashima T, Tai T: Immunohistochemical localization of minor gangliosides in the rat central nervous system. Glycobiology 1994, 4:855-865.

20. Tomasello F, Messina A, Lartigue L, Schembri L, Medina C, Reina S, Thoraval D, Crouzet M, Ichas F, De Pinto V, De Giorgi F: Outer membrane VDAC1 controls permeability transition of the inner mitochondrial membrane in cellulo during stress-induced apoptosis. Cell Res 2009, 19:1363-1376.

21. Bender A, Krishnan KJ, Morris CM, Taylor GA, Reeve AK, Perry RH, Jaros E, Hersheson JS, Betts J, Klopstock T, et al: High levels of mitochondrial DNA deletions in substantia nigra neurons in aging and Parkinson disease. Nat Genet 2006, 38:515-517.

22. Hayashi Y, Yoshida M, Yamato M, Ide T, Wu Z, Ochi-Shindou M, Kanki T, Kang D, Sunagawa K, Tsutsui H, Nakanishi H: Reverse of age-dependent memory impairment and mitochondrial DNA damage in microglia by an overexpression of human mitochondrial transcription factor a in mice. The Journal of neuroscience: the official journal of the Society for Neuroscience 2008, 28:8624-8634.

23. Ubhi K, Lee $\mathrm{PH}$, Adame A, Inglis C, Mante M, Rockenstein E, Stefanova N, Wenning GK, Masliah E: Mitochondrial inhibitor 3-nitroproprionic acid enhances oxidative modification of alpha-synuclein in a transgenic mouse model of multiple system atrophy. J Neurosci Res 2009, 87:2728-2739

24. Belin AC, Westerlund M: Parkinson's disease: a genetic perspective. FEBS J 2008, 275:1377-1383.

25. Satake W, Nakabayashi Y, Mizuta I, Hirota Y, Ito C, Kubo M, Kawaguchi T, Tsunoda T, Watanabe M, Takeda A, et al: Genome-wide association study identifies common variants at four loci as genetic risk factors for Parkinson's disease. Nat Genet 2009, 41:1303-1307.

26. Shin $\mathrm{N}$, Jeong H, Kwon J, Heo HY, Kwon JJ, Yun HJ, Kim CH, Han BS, Tong Y, Shen J, et al: LRRK2 regulates synaptic vesicle endocytosis. Exp Cell Res 2008, 314:2055-2065.

27. Biskup S, Moore DJ, Celsi F, Higashi S, West AB, Andrabi SA, Kurkinen K, Yu SW, Savitt JM, Waldvogel HJ, et al: Localization of LRRK2 to membranous and vesicular structures in mammalian brain. Ann Neurol 2006, 60:557-569.

28. Giasson BI, Covy JP, Bonini NM, Hurtig HI, Farrer MJ, Trojanowski JQ, Van Deerlin VM: Biochemical and pathological characterization of Lrrk2. Ann Neurol 2006, 59:315-322.

29. Melrose HL, Kent CB, Taylor JP, Dachsel JC, Hinkle KM, Lincoln SJ, Mok SS, Culvenor JG, Masters CL, Tyndall GM, et al: A comparative analysis of leucine-rich repeat kinase 2 (Lrrk2) expression in mouse brain and Lewy body disease. Neuroscience 2007, 147:1047-1058.

30. Yang DS, Lee $J H$, Nixon RA: Monitoring autophagy in Alzheimer's disease and related neurodegenerative diseases. Methods Enzymol 2009, 453:111-144.

31. Kragh CL, Ubhi K, Wyss-Corey T, Masliah E: Autophagy in dementias. Brain Pathol 2012, 22:99-109.

32. Martin LJ, Pan Y, Price AC, Sterling W, Copeland NG, Jenkins NA, Price DL, Lee MK: Parkinson's disease alpha-synuclein transgenic mice develop neuronal mitochondrial degeneration and cell death. The Journal of neuroscience: the official journal of the Society for Neuroscience 2006, 26:41-50.

33. Bosco DA, Fowler DM, Zhang Q, Nieva J, Powers ET, Wentworth P Jr, Lerner RA, Kelly JW: Elevated levels of oxidized cholesterol metabolites in Lewy body disease brains accelerate alpha-synuclein fibrilization. Nat Chem Biol 2006, 2:249-253

34. MacLeod D, Dowman J, Hammond R, Leete T, Inoue K, Abeliovich A: The familial Parkinsonism gene LRRK2 regulates neurite process morphology. Neuron 2006, 52:587-593.

35. Li Y, Liu W, Oo TF, Wang L, Tang Y, Jackson-Lewis V, Zhou C, Geghman K, Bogdanov M, Przedborski S, et al: Mutant LRRK2(R1441G) BAC transgenic mice recapitulate cardinal features of Parkinson's disease. Nat Neurosci 2009, 12:826-828.

36. Lin X, Parisiadou L, Gu XL, Wang L, Shim H, Sun L, Xie C, Long CX, Yang WJ, Ding J, et al: Leucine-rich repeat kinase 2 regulates the progression of neuropathology induced by Parkinson's-disease-related mutant alpha-synuclein. Neuron 2009, 64:807-827.
37. Rockenstein E, Mallory M, Hashimoto M, Song D, Shults CW, Lang I, Masliah E: Differential neuropathological alterations in transgenic mice expressing alpha-synuclein from the platelet-derived growth factor and Thy-1 promoters. J Neurosci Res 2002, 68:568-578.

38. Kubota Y, Hatada SN, Kawaguchi Y: Important factors for the three-dimensional reconstruction of neuronal structures from serial ultrathin sections. Frontiers in Neural Circuits 2009, 3:4.

39. Maruyama M, Matsumoto H, Fujiwara K, Kitada C, Hinuma S, Onda H, Fujino $\mathrm{M}$, Inoue K: Immunocytochemical localization of prolactin-releasing peptide in the rat brain. Endocrinology 1999, 140:2326-2333.

40. Schultz A: Eine Methode des mikrochemischen Cholesterinnachweises am Gewebsschnitt. Zentralblatt fur Allgemeine pathologie und Pathologische Anatomie 1924, 35:314-317.

doi:10.1186/1756-6606-5-34

Cite this article as: Sekigawa et al:: Distinct mechanisms of axonal globule formation in mice expressing human wild type a-synuclein or dementia with Lewy bodies-linked P123H ß-synuclein. Molecular Brain 2012 5:34.

\section{Submit your next manuscript to BioMed Central and take full advantage of:}

- Convenient online submission

- Thorough peer review

- No space constraints or color figure charges

- Immediate publication on acceptance

- Inclusion in PubMed, CAS, Scopus and Google Scholar

- Research which is freely available for redistribution 